\title{
Design of distribution substation earth grid in high resistivity soil using CDEGS
}

\begin{abstract}
Design of distribution substation earthing grid can be very challenging in high resistivity soils especially in two layer soils where the top layer resistivity is lower than the bottom layer. This paper presents the design of a distribution substation earth grid using Current Distribution Electromagnetic Field Grounding Soil Structure Analysis Software (CDEGS). Soil resistivity measurement was carried out at the substation site using a 4-pole Megger earth tester based on Wenner method. The soil structure was determined using RESAP module, while the design was implemented using SESCAD and executed by MALT module. Results indicated a slight reduction of earth grid resistance, $0.6 \%, 5.8 \%$ and $6.5 \%$, respectively as the grid burial depth was varied from $0.5 \mathrm{~m}$ to $1.5 \mathrm{~m}$ in steps of $0.5 \mathrm{~m}$. The touch and step voltages were found to be lower when surface layer material was not applied and higher when surface layer materials of 3000Q-m and 5000Q-m resistivity were interchangeably applied on the grid surface. It was also found that, the calculated earth grid resistance from IEEE Std. 80-2000 equation was lower than the grid resistance computed by MALT.
\end{abstract}

